\title{
Antimicrobial resistance in urinary isolates from inpatients and outpatients at a tertiary care hospital in South-Kivu Province (Democratic Republic of Congo)
}

Leonid M Irenge ${ }^{1,2,3^{*}}$, Landry Kabego ${ }^{1}$, Olivier Vandenberg ${ }^{4}$, Raphael B Chirimwami ${ }^{1}$ and Jean-Luc Gala ${ }^{2,3}$

\begin{abstract}
Background: The rate of antimicrobial resistant isolates among pathogens causing urinary tract infections (UTIS) in Democratic Republic of Congo (DRC) is not known. The aim of the current study was to determine this rate at the Bukavu Provincial General Hospital (province of South-Kivu, DRC).

Findings: A total of 643 isolates (both from inpatients and outpatients) collected from September 2012 to August 2013 were identified using biochemical methods, and tested for antimicrobial susceptibility. The isolates were further screened for Extended-Spectrum Beta-Lactamases (ESBL) production. Beta-lactamase AmpC phenotype was investigated in 20 antibiotic-resistant isolates.

Escherichia coli (58.5\%), Klebsiella spp. (21.9\%) and Enterobacter spp. (16.2\%) were the most frequent uropathogens encountered. Rare uropathogens included Citrobacter spp., Proteus spp., and Acinetobacter spp. Resistance was significantly more present in inpatients isolates ( $22.1 \%$ of isolates) when compared to outpatients isolates ( $8.4 \%$ of isolates), (p-value $<0.001$ ). Antibiotic-resistant isolates displayed resistance to common antimicrobial drugs used for UTIs treatment in South Kivu province, namely: ciprofloxacin, ampicillin and third generation cephalosporins. ESBL-phenotype was present in $92.9 \%$ of antibiotic-resistant isolates. Only amikacin, nitrofurantoin and imipenem displayed satisfactory activity against antibiotic resistant isolates.
\end{abstract}

Conclusions: This study confirms the presence of antibiotic-resistant uropathogens (mainly ESBL-producers isolates) at the Bukavu General Hospital. This study should serve as a wake-up call and help to raise awareness about the threat to public health of antibiotic resistance in this DRC province.

Keywords: Urinary tract infections, South-Kivu, Democratic Republic of Congo, Multidrug resistance, Prevalence, Extended spectrum beta-lactamases, Antibotics

\section{Introduction}

Urinary tract infections (UTIs) refer to any type of urothelial inflammatory response resulting from the invasion of the urinary tract by microbial pathogens $[1,2]$. They are considered to be the most common bacterial infections worldwide, whether in the community or hospital setting

\footnotetext{
* Correspondence: leonid.irenge@uclouvain.be

${ }^{1}$ Bukavu General Hospital/Université Catholique de Bukavu, P.O. Box 285, Bukavu, Democratic Republic of Congo

${ }^{2}$ Center for Applied Molecular Technologies, Institut de Recherche Expérimentale et Clinique, Université catholique de Louvain, Clos chapelle-aux-champs, 30 B1.30.24, 1200 Brussels, Belgium

Full list of author information is available at the end of the article
}

[3-5]. While UTIs are well documented worldwide [6-20], there are currently no reports on UTIs prevalence in DRC, the second largest Africa country. The country has been plagued by a protracted civilian war which has claimed an estimated five million lives [21], with nearly $60 \%$ of all deaths caused by infectious diseases [22-24].

Accordingly, the aim of this study was to monitor the rate of resistant urinary pathogens isolated from patients with UTIs (both from community and hospital settings) attending Bukavu Provincial Hospital (South Kivu, DRC) from September 2012 to August 2013, as well as to 
determine the pattern of antibiotic resistance to commonly used antimicrobial agents in the province.

\section{Materials and methods}

\section{Study population and bacterial isolates}

This cross-sectional study was conducted in both outpatients and inpatients suspected of UTI at the Bukavu Provincial Hospital. This hospital is one of the main healthcare facilities of Bukavu, a city of more than 500 000 inhabitants. The hospital also serves as the health reference center for the province of South-Kivu. It has 385 beds with 6400 admissions and 4900 outpatients per year.

Urinary samples were collected in sterile universal containers from patients presenting with UTI symptoms (dysuria, pelvic pain, with or without fever) from September 2012 to August 2013. Exclusion factors were structural or functional abnormalities of the genitourinary tract. Catheterized patients were also excluded. Samples were cultured within 30 minutes of collection. Samples displaying pyuria (white blood cell count greater than 5 per high-power field upon light microscopic examination) and/or bacteriuria $10^{5} \mathrm{CFU}$ per $\mathrm{mL}$ were further processed for culture and subsequent antimicrobial susceptibility testing. Each specimen was cultured using a $10 \mu \mathrm{L}$ calibrated loop to inoculate cysteine lactose electrolytes deficient (CLED) agar and incubated at $37^{\circ} \mathrm{C}$ for $16-24$ hours and the number of colonies was counted. A growth of $>10^{5}$ colony forming units $/ \mathrm{mL}$ of one type of organism was considered as significant bacteriuria. Identification was performed using standard biochemical tests [25].

Ethical approval for the study was granted by the Institutional Review Board (IRB) of the Université Catholique de Bukavu, DRC. The study complied with the World Health Organization and international guidelines on antibiotic surveillance for which no recommendation for an informed consent has been issued. In order to ensure confidentiality, samples were analyzed anonymously.

\section{Antimicrobial susceptibility testing}

The isolates were tested by the disk diffusion method on Muller Hinton agar II and the results were interpreted according to the guidelines European Committee on Antimicrobial Susceptibility Testing (EUCAST, 2013) [26]. Antibiotic disks were purchased from Bio-Rad (Nazareth Eke, Belgium). The following antibiotics were tested: amikacin, ampicillin, amoxicillin, amoxicillin-clavulanic acid, ceftriaxone, ceftazidime, imipenem, trimethoprimsulfamethoxazole, amikacin, ciprofloxacin, nitrofurantoin. Isolates showing resistance to at least one cephalosporin were tested for ESBL production by the double-disk synergy test on Mueller-Hinton agar (Biorad, Nazareth Eke; Belgium) using ceftazidime and ceftriaxone placed at a distance of $20 \mathrm{~mm}$ apart from a disk containing amoxicillin plus clavulanic acid. A clear-cut enhancement of the inhibition in front of either ceftazidime and ceftriaxone disks towards the clavulanic acid-containing disk (also called "champagne-cork" or "keyhole") was interpreted as positive for ESBL production [27]. E-test strips (BioMérieux, Marcy l'Etoile, France) were used for confirmation of ESBL production. Minimum inhibitory concentrations (MIC) of cefotaxime and ceftazidime with and without clavulanic acid were determined, after 16-18 hours incubation on Mueller Hinton plates inoculated with suspension of isolates at a fixed density ( 0.5 to 0.6 McFarland standard). The test was performed and interpreted according to the manufacturer's instructions. Escherichia coli ATCC 35218 and Klebsiella pneumoniae ATCC 700603 strains were used as ESBL negative and positive controls respectively. Twenty ampicillin and/or third-generation cephalosporins-resistant isolates $(n=20)$ were tested for the presence of the betalactamase AmpC phenotype, using cefoxitin-cloxacillin disk diffusion test as described by Tan et al. [28]. Multi-drug resistance was defined as non-susceptibility to at least one agent in three or more antimicrobial categories [29]. All multi-drug resistant isolates were cryopreserved at $-80^{\circ} \mathrm{C}$ for further studies.

\section{Statistical analysis}

Statistical analyses were performed using the SPSS statistical package release 12.0 for Windows (SPSS, Inc., Chicago, IL). Differences in group proportions and categorical variables were assessed using the chi-square test. A $p$-value $<0.05$ was considered as statistically significant.

\section{Findings}

Clean-catch midstream urine specimens $(\mathrm{n}=2724)$ were processed during the 12-month study period (from September $1^{\text {st }} 2012$ until August $31^{\text {st }}$ 2013) among which 1130 (41.2\%), and 1594 (58.5\%) were sampled from outpatients and inpatients, respectively. Of these 2724 samples, $643(23.6 \%)$ yielded significant growth of a single organism. Among positive samples $(n=643), 35.0 \%$, and $65.0 \%$ were isolated from outpatients and inpatients respectively. The mean age of the study population was 27.2 years, with a range of $0-75$ years. Children between 0 and 17 years represented $20.6 \%$ of all patients. The female to male ratio was 1.73 .

Escherichia coli was the most frequent uropathogen isolated (376 out of $643 ; 58.5 \%$ ) at the Bukavu General Hospital both in outpatients and in inpatients. Klebsiella spp. and Enterobacter spp. represented 21.9\% and 16.2\% of uropathogens. Rare uropathogens included Citrobacter spp., Proteus spp., and Acinetobacter spp. A summary of antimicrobial susceptibility patterns of the most frequent uropathogens is presented in Table 1.

$16.3 \%$ isolates $(n=643)$ displayed a MDR phenotype. Multidrug resistance rate was higher in inpatients isolates 
Table 1 Antibiotic-resistance global rate $(\%)$ of UTI isolates $(n=643)$ collected at the Bukavu Hospital, South Kivu, DRC

\begin{tabular}{|c|c|c|c|c|c|c|}
\hline Antimicrobial drug & $\begin{array}{l}\text { Escherichia coli } \\
(\mathrm{n}=376)\end{array}$ & $\begin{array}{l}\text { Klebsiella spp. } \\
(\mathrm{n}=146)\end{array}$ & $\begin{array}{l}\text { Enterobacter spp. } \\
(\mathrm{n}=104)\end{array}$ & $\begin{array}{l}\text { Citrobacter spp. } \\
(\mathrm{n}=18)^{*}\end{array}$ & $\begin{array}{l}\text { Proteus spp. } \\
(\mathrm{n}=2)^{*}\end{array}$ & $\begin{array}{l}\text { Acinetobacter spp. } \\
(n=2)^{*}\end{array}$ \\
\hline Amikacin & 9.3 & 2.7 & 2.9 & 5.6 & 100 & 0 \\
\hline Amoxycillin & 16.0 & 13.7 & 17.3 & 16.7 & 100 & 100 \\
\hline Ampicillin & 16.0 & 13.7 & 17.3 & 16.7 & 100 & 100 \\
\hline Amoxicillin/clavulanic acid & 16.0 & 13.7 & 15.4 & 11.7 & 100 & 0 \\
\hline Ceftazidime & 16.0 & 13.7 & 17.3 & 16.7 & 100 & 100 \\
\hline Ceftriaxone & 15.7 & 13.7 & 17.3 & 16.7 & 100 & 100 \\
\hline Cefuroxine & 15.7 & 13.7 & 17.3 & 16.7 & 100 & 100 \\
\hline Ciprofloxacine & 15.4 & 11.7 & 14.4 & 16.7 & 100 & 100 \\
\hline Imipenem & 0 & 0 & 1 & 0 & 0 & 0 \\
\hline Nitrofurantoin & 3.5 & 2.1 & 4.8 & 0 & 0 & 0 \\
\hline Sulfamethoxazole/Trimethoprim & 15.4 & 13.7 & 17.3 & 16.7 & 100 & 100 \\
\hline
\end{tabular}

*Caution regarding antibiotic-resistance rates, given the low number of isolates assayed.

(22.1\%) compared to outpatients (8.4\%) (p-value <0.001). Among these MDR isolates, $92.4 \%$ displayed an ESBL phenotype. Nitrofurantoin susceptibility for E. coli, Enterobacter spp. and Klebsiella spp. was 69.6\%, 78.9\%, and $83.3 \%$, respectively. Uropathogens susceptibility rates to amikacin were $42.1 \%, 69.6 \%$ and $77.8 \%$ for $E$. coli, Enterobacter spp. and Klebsiella spp., respectively. Regarding imipenem, all isolates but one, were susceptible in vitro. This single imipenem non-susceptible isolate was identified as an Enterobacter spp. Preliminary molecular data obtained on 25 isolates showed that the CTX-M group 1 gene was the most common in ESBL-producing isolates assayed. Regarding beta-lactamases AmpC, no isolate out of the 20 isolates assayed displayed this phenotype.

\section{Discussion}

The steady increase of bacteria resistance to antibiotics is a cause of global concern. Infections caused by resistant microorganisms often fail to respond to the standard treatment, resulting in prolonged illness and greater risk of death [30]. Available studies from several Sub-Saharian countries in Africa have highlighted unexpected high levels of resistance of uropathogens to common antibiotics [9-12,14,16,17,31]. Unfortunately, there are no data on rates of antibiotic resistance of uropathogens in DRC. In that respect, recent data on Salmonella isolates from blood cultures in DRC have shown high levels of antibiotic resistance [32-34].

Accordingly, the goal of this work was to provide a benchmark for the prevalence and patterns of antibiotic resistance of bacterial pathogens involved in UTIs at the Bukavu General Hospital. This study confirmed that E. coli was the most common bacterial uropathogen isolated from both in inpatients and outpatients at the
Bukavu Hospital. Besides E.coli, other bacterial species such as Klebsiella spp. and Enterobacter spp. were also frequently encountered. Noteworthy, we were not able to isolate any Group B Streptococcus (GBS), though GBS have been reported as causative agents of UTIs [35]. This possible bias might be linked to the sole use of CLED medium for uropathogens isolation. It has indeed been previously reported that the identification of Streptococcus agalactiae on CLED agar could be challenging [36].

Limitations also include the possibility of selection bias due to the fact that Bukavu Hospital mostly deals with patients who had been treated with antibiotics prior to their visit. Finally, our study may have underestimated the prevalence of UTIs by using our current threshold of $10^{5} \mathrm{CFU} / \mathrm{mL}$ of urine sample as a pre-requisite for urine culture. Several studies have shown indeed that using lower CFU threshold values improve the identification of UTIs [37,38].

Our study found that the overall prevalence of antibacterial drug resistance was lower than recently reported in neighboring countries [12,20]. A recent study in neighboring Rwanda reported resistance rates of $59.2 \%, 32.1 \%$ and $41.3 \%$ for amoxicillin/clavulanic acid, ceftriaxone and ciprofloxacillin, respectively [20].

Regarding the pattern of resistance in the 105 drugresistant isolates, there was a striking low susceptibility to ampicillin, amoxicillin, amoxicillin/clavulanic, cefuroxime, ceftazidime, ceftriaxone, ciprofloxacin and sulfamethoxazole/trimethoprim (see Table 2). Conversely, susceptibility rates for rare pathogens as reported in this study (Citrobacter spp., Proteus spp.and Acinetobacter spp.) should be interpreted with caution, as they were based on a restricted number of isolates, and could therefore result in observational bias with overestimation of effect size. Interestingly, this study showed that ESBL-production 
Table 2 Antibiotic resistance rates among MDR uropathogen isolates $(n=105)$ at the Bukavu General Hospital

\begin{tabular}{|c|c|c|c|c|c|c|}
\hline Antimicrobial agent & $\begin{array}{l}\text { E. coli } \\
(\mathrm{n}=57)\end{array}$ & $\begin{array}{l}\text { Enterobacter spp. } \\
(\mathrm{n}=23)\end{array}$ & $\begin{array}{l}\text { Klebsiella spp. } \\
(\mathrm{n}=18)\end{array}$ & $\begin{array}{l}\text { Citrobacter spp.* } \\
(\mathrm{n}=3)\end{array}$ & $\begin{array}{l}\text { Proteus spp* } \\
(\mathrm{n}=2)\end{array}$ & $\begin{array}{l}\text { Acinetobacter spp* } \\
(\mathrm{n}=2)\end{array}$ \\
\hline ESBL-producing (\%) phenotype & 98.2 & 100.0 & 100.0 & 100.0 & 100.0 & 0 \\
\hline Amikacin (\%) & 57.9 & 30.4 & 22.2 & 33.3 & 100.0 & 0 \\
\hline Amoxycillin (\%) & 100.0 & 100.0 & 100.0 & 100.0 & 100.0 & 100.0 \\
\hline Ampicillin (\%) & 100.0 & 100.0 & 100.0 & 100.0 & 100.0 & 100.0 \\
\hline Amoxicillin/clavulanic acid (\%) & 84.2 & 87.0 & 100.0 & 66.7 & 100.0 & 0 \\
\hline Ceftazidime (\%) & 100.0 & 100.0 & 100.0 & 100.0 & 100.0 & 100.0 \\
\hline Ceftriaxone (\%) & 98.2 & 100.0 & 100.0 & 100.0 & 100.0 & 100.0 \\
\hline Cefuroxine (\%) & 98.2 & 100.0 & 100.0 & 100.0 & 100.0 & 100.0 \\
\hline Ciprofloxacine (\%) & 96.5 & 82.6 & 83.3 & 100.0 & 100.0 & 100.0 \\
\hline Imipenem (\%) & 0 & 4.3 & 0 & 0 & 0 & 0 \\
\hline Nitrofurantoin (\%) & 21.1 & 30.4 & 16.7 & 0 & 0 & 0 \\
\hline Sulfamethoxazole/trimethopim (\%) & 96.5 & 100.0 & 100.0 & 100.0 & 100.0 & 100.0 \\
\hline
\end{tabular}

*Caution regarding antibiotic-resistance rates, given the low number of isolates assayed.

was the main mechanism of resistance both in outpatients and inpatients at the Bukavu hospital. Global susceptibility rate of uropathogens to nitrofurantoin was $78.6 \%$. The susceptibility of antibiotic-resistant isolates to amikacin, nitrofurantoin and to imipenem was high, which is a significant observation in terms of management of UTIs. To the best of our knowledge, this is the first study in DRC (South-Kivu Province) on the rate of resistant and/or ESBL-producing uropathogens.

Carbapenems have been recently introduced in the province for treatment of ESBL-producing Enterobacteria, and this study demonstrated very high susceptibility among uropathogens. Based on our findings, we advocate prescription of nitrofurantoin as the first-line antibiotics for UTIs treatment in South Kivu. Despite high susceptibility to imipenem, it is critical to warn physicians about the danger of prescribing this compound as first-line antibiotic for UTIs treatment, because this habit will likely enhance the emergence of imipenemresistant bacteria. Likewise, several other antibiotics previously reported as active against uropathogens in other studies [7,39-41] but not currently prescribed in South Kivu should be tested against MDR-resistant uropathogens. These include drugs such as Fosfomycin [42], Piperacillin/ Tazobactam [39], Fosmomycin/tromethamol [40], cefepime, tigecycline, temocillin $[7,41]$ and other carbapemens [19]. But most importantly, it will be important to put emphasis on public and professional education towards a rational use of antibiotics, i.e. antibiotherapy based on susceptibility patterns of pathogens, promotion and evaluation of medical and veterinary practice guidelines. Curbing the spread of antibiotic resistant pathogens in the province and in the country will also entail to deal with other critical issues which should be investigated. These include controlling the influx of counterfeit drugs, and dealing with issues related to affordability of healthcare in the province.

\section{Conclusions}

High rates of ESBL-producing Gram-negative bacteria were found among inpatients and outpatients at the Bukavu Hospital in DR Congo. Most of these ESBL-producing isolates were also multidrug resistant, except for amikacin, nitrofurantoin and imipenem for which susceptibility was high.

\section{Competing interests}

The authors declare that they have no competing interests.

\section{Authors' contributions}

LMI, LK, OV, RBC and JLG participated in the design of the study. LMI oversaw the whole collection of data. LMI and LK were responsible for the laboratory assays. LMI drafted the first manuscript and all co-authors participated in the manuscript revision. All authors read and approved the final manuscript.

\section{Acknowledgments}

We thank the staff of the Clinical Biology Department at the Bukavu Provincial Hospital for their technical assistance. We also gratefully acknowledge the assistance of Yann Deccache (IRSD-RSTD), Marine Vanghomwegen (Hogeschool Gent), and Benjamin Smits (Haute Ecole Leonard de Vinci) for their technical input during the completion of this work.

Financial support: This project was funded by Belgian Cooperation Agency through the 2012 PIC project ("Projet Inter-universitaire de Coopération") of the CUD (Coopération Universitaire pour le Développement) and by Department Management of Scientific \& Technological Research of Defence (IRSD-RSTD; Royal High Institute for Defence) supporting research and development (grants MED-20).

\section{Author details}

${ }^{1}$ Bukavu General Hospital/Université Catholique de Bukavu, P.O. Box 285, Bukavu, Democratic Republic of Congo. ${ }^{2}$ Center for Applied Molecular Technologies, Institut de Recherche Expérimentale et Clinique, Université catholique de Louvain, Clos chapelle-aux-champs, 30 B1.30.24, 1200 Brussels, Belgium. ${ }^{3}$ Defense Laboratories Department, ACOS Ops\&Trg, Belgian Armed 
Forces, Martelarenstraat, 181, 1800 Peutie, Belgium. ${ }^{4}$ Infectious Diseases Epidemiological Unit, Public Health School, Université Libre de Bruxelles, Brussels, Belgium.

Received: 18 December 2013 Accepted: 13 June 2014

Published: 18 June 2014

\section{References}

1. Dielubanza EJ, Schaeffer AJ: Urinary tract infections in women. Med Clin North Am 2011, 95:27-41.

2. Foxman B: Epidemiology of urinary tract infections: incidence, morbidity, and economic costs. Am J Med 2002, 113(Suppl 1A):5S-13S.

3. Ronald AR, Nicolle LE, Stamm E, Krieger J, Warren J, Schaeffer A, Naber KG, Hooton TM, Johnson J, Chambers S, Andriole V: Urinary tract infection in adults: research priorities and strategies. Int J Antimicrob Agents 2001, 17:343-8.

4. Olson RP, Harrell $\sqcup$, Kaye KS: Antibiotic resistance in urinary isolates of Escherichia coli from college women with urinary tract infections. Antimicrob Agents Chemother 2009, 53:1285-6.

5. Steinke DT, Seaton RA, Phillips G, MacDonald TM, Davey PG: Prior trimethoprim use and trimethoprim-resistant urinary tract infection: a nested case-control study with multivariate analysis for other risk factors. J Antimicrob Chemother 2001, 47:781-7.

6. Gopal Rao G, Patel M: Urinary tract infection in hospitalized elderly patients in the United Kingdom: the importance of making an accurate diagnosis in the post broad-spectrum antibiotic era. J Antimicrob Chemother 2009, 63:5-6.

7. Pallett $\mathrm{A}$, Hand $\mathrm{K}$ : Complicated urinary tract infections: practical solutions for the treatment of multiresistant Gram-negative bacteria. J Antimicrob Chemother 2010, 65(Suppl 3):iii25-33.

8. Shaikh N, Morone NE, Bost JE, Farrell MH: Prevalence of urinary tract infection in childhood: a meta-analysis. Pediatr Infect Dis J 2008, 27:302-8.

9. Beyene $\mathrm{G}$, Tsegaye $\mathrm{W}$ : Bacterial uropathogens in urinary tract infection and antibiotic susceptibility pattern in jimma university specialized hospital, southwest ethiopia. Ethiop J Health Sci 2011, 21:141-6.

10. Sire JM, Nabeth P, Perrier-Gros-Claude JD, Bahsoun I, Siby T, Macondo EA, Gaye-Diallo A, Guyomard S, Seck A, Breurec S, Garin B: Antimicrobial resistance in outpatient Escherichia coli urinary isolates in Dakar, Senegal. $\int$ Infect Dev Ctries 2007, 1:263-8

11. Dromigny JA, Nabeth P, Juergens-Behr A, Perrier-Gros-Claude JD: Risk factors for antibiotic-resistant Escherichia coli isolated from community-acquired urinary tract infections in Dakar, Senegal. J Antimicrob Chemother 2005, 56:236-9.

12. Moyo SJ, Aboud S, Kasubi M, Lyamuya EF, Maselle SY: Antimicrobial resistance among producers and non-producers of extended spectrum beta-lactamases in urinary isolates at a tertiary Hospital in Tanzania. BMC Res Notes 2010, 3:348.

13. Muvunyi CM, Masaisa F, Bayingana C, Mutesa L, Musemakweri A, Muhirwa G, Claeys GW: Decreased susceptibility to commonly used antimicrobial agents in bacterial pathogens isolated from urinary tract infections in Rwanda: need for new antimicrobial guidelines. Am J Trop Mad Hyg 2011, 84:923-8.

14. Dada-Adegbola HO, Muili KA: Antibiotic susceptibility pattern of urinary tract pathogens in Ibadan, Nigeria. Afr J Med Med Sci 2010, 39:173-9.

15. Mandomando I, Sigaúque B, Morais L, Espasa M, Vallès X, Sacarlal J, Macete E, Aide P, Quintò L, Nhampossa T, Machevo S, Bassat Q, Menéndez C, Ruiz J, Roca A, Alonso PL: Antimicrobial drug resistance trends of bacteremia isolates in a rural hospital in southern Mozambique. Am J Trop Med Hyg 2010, 83:152-7.

16. Bercion R, Mossoro-Kpinde D, Manirakiza A, Le Faou A: Increasing prevalence of antimicrobial resistance among Enterobacteriaceae uropathogens in Bangui, Central African Republic. J Infect Dev Ctries 2009, 3:187-90.

17. Alabi AS, Frielinghaus L, Kaba H, Kösters K, Huson MA, Kahl BC, Peters G, Grobusch MP, Issifou S, Kremsner PG, Schaumburg F: Retrospective analysis of antimicrobial resistance and bacterial spectrum of infection in Gabon, Central Africa. BMC Infect Dis 2013, 13:455.

18. Babypadmini S, Appalaraju B: Extended spectrum -lactamases in urinary isolates of Escherichia coli and Klebsiella pneumoniae - prevalence and susceptibility pattern in a tertiary care hospital. Indian J Med Microbiol 2004, 22:172-4.
19. Hsueh PR, Hoban DJ, Carmeli Y, Chen SY, Desikan S, Alejandria M, Ko WC, Binh TQ: Consensus review of the epidemiology and appropriate antimicrobial therapy of complicated urinary tract infections in Asia-Pacific region. J Infect 2011, 63:114-23.

20. Muvunyi CM, Masaisa F, Bayingana C, Mutesa L, Musemakweri A, Muhirwa G, Claeys GW: Decreased susceptibility to commonly used antimicrobial agents in bacterial pathogens isolated from urinary tract infections in Rwanda: need for new antimicrobial guidelines. Am J Trop Med Hyg 2011, 84:923-8.

21. Moszynski P: 5.4 million people have died in Democratic Republic of Congo since 1998 because of conflict, report says. BMJ 2008, 336:235.

22. Gayer M, Legros D, Formenty P, Connolly MA: Conflict and emerging infectious diseases. Emerg Infect Dis 2007, 13:1625-31.

23. Van Herp M, Parque V, Rackley E, Ford N: Mortality, violence and lack of access to healthcare in the Democratic Republic of Congo. Disasters 2003, 27:141-53.

24. Coghlan B, Brennan RJ, Ngoy P, Dofara D, Otto B, Clements M, Stewart T: Mortality in the Democratic Republic of Congo: a nationwide survey. Lancet 2006, 367:44-51.

25. Isenberg HD: Essential procedures for clinical microbiology. Washington, D.C.: ASM Press; 1998

26. Testing, E.C.O.A.S: Breakpoint tables for interpretation of MICS and zone diameters. ed.^eds); 2013.

27. Drieux L, Brossier F, Sougakoff W, Jarlier V: Phenotypic detection of extendedspectrum beta-lactamase production in Enterobacteriaceae: review and bench guide. Clin Microbiol Infect 2008, 14(Suppl 1):90-103.

28. Tan TY, Ng LS, He J, Koh TH, Hsu LY: Evaluation of screening methods to detect plasmid-mediated AmpC in Escherichia coli, Klebsiella pneumoniae, and Proteus mirabilis. Antimicrob Agents Chemother 2009, 53:146-9.

29. Magiorakos AP, Srinivasan A, Carey RB, Carmeli Y, Falagas ME, Giske CG, Harbarth S, Hindler JF, Kahlmeter G, Olsson-Liljequist B, Paterson DL, Rice LB, Stelling J, Struelens MJ, Vatopoulos A, Weber JT, Monnet DL: Multidrug-resistant, extensively drug-resistant and pandrug-resistant bacteria: an international expert proposal for interim standard definitions for acquired resistance. Clin Microbiol Infect 2012, 18:268-81.

30. Spellberg B, Guidos R, Gilbert D, Bradley J, Boucher HW, Scheld WM, Bartlett $J G$, Edwards J Jr, Infectious Diseases Society of America: The epidemic of antibiotic-resistant infections: a call to action for the medical community from the Infectious Diseases Society of America. Clin Infect Dis 2008, 46:155-64

31. Peirano G, Ahmed-Bentley J, Woodford N, Pitout JD: New Delhi metallo-beta-lactamase from traveler returning to Canada. Emerg Infect Dis 2011, 17:242-4

32. Vandenberg O, Nyarukweba DZ, Ndeba PM, Hendriksen RS, Barzilay EJ Schirvel C, Bisimwa BB, Collard JM, Aidara Kane A, Aarestrup FM: Microbiologic and clinical features of Salmonella species isolated from bacteremic children in eastern Democratic Republic of Congo. Pediatr Infect Dis J 2010, 29:504-10.

33. Lunguya O, Lejon V, Phoba MF, Bertrand S, Vanhoof R, Verhaegen J, Smith AM, Keddy KH, Muyembe-Tamfum JJ, Jacobs J: Salmonella typhi in the democratic republic of the congo: fluoroquinolone decreased susceptibility on the rise. PLoS Negl Trop Dis 2012, 6:e1921.

34. Phoba MF, De Boeck H, Ifeka BB, Dawili J, Lunguya O, Vanhoof R, Muyembe $\mathrm{J}$, Van Geet C, Bertrand S, Jacobs J: Epidemic increase in Salmonella bloodstream infection in children, Bwamanda, the Democratic Republic of Congo. Eur J Clin Microbiol Infect Dis 2014, 33:79-87.

35. Ulett KB, Benjamin WH Jr, Zhuo F, Xiao M, Kong F, Gilbert GL, Schembri MA, Ulett GC: Diversity of group B streptococcus serotypes causing urinary tract infection in adults. J Clin Microbiol 2009, 47:2055-60.

36. Jokipii AM, Jokipii L: Recognition of group B streptococci in dip-slide cultures of urine. J Clin Microbiol 1979, 10:218-21.

37. Giesen $L G$, Cousins G, Dimitrov BD, van de Laar FA, Fahey T: Predicting acute uncomplicated urinary tract infection in women: a systematic review of the diagnostic accuracy of symptoms and signs. BMC Fam Pract 2010, 11:78.

38. Tan CK, Ulett KB, Steele M, Benjamin WH Jr, Ulett GC: Prognostic value of semi-quantitative bacteruria counts in the diagnosis of group $B$ streptococcus urinary tract infection: a 4-year retrospective study in adult patients. BMC Infect Dis 2012, 12:273. 
39. Mathai D, Lewis MT, Kugler KC, Pfaller MA, Jones RN: Antibacterial activity of 41 antimicrobials tested against over 2773 bacterial isolates from hospitalized patients with pneumonia: I-results from the SENTRY Antimicrobial Surveillance Program (North America, 1998). Diagn Microbiol Infect Dis 2001, 39:105-16.

40. Keating GM: Fosfomycin trometamol: a review of its use as a single-dose oral treatment for patients with acute lower urinary tract infections and pregnant women with asymptomatic bacteriuria. Drugs 2013, 73:1951-66.

41. Balakrishnan I, Awad-El-Kariem FM, Aali A, Kumari P, Mulla R, Tan B, Brudney D, Ladenheim D, Ghazy A, Khan I, Virgincar N, lyer S, Carryn S, Van de Velde S: Temocillin use in England: clinical and microbiological efficacies in infections caused by extended-spectrum and/or derepressed AmpC beta-lactamase-producing Enterobacteriaceae. J Antimicrob Chemother 2011, 66:2628-31.

42. Neuner EA, Sekeres J, Hall GS, van Duin D: Experience with fosfomycin for treatment of urinary tract infections due to multidrug-resistant organisms. Antimicrob Agents Chemother 2012, 56:5744-8.

doi:10.1186/1756-0500-7-374

Cite this article as: Irenge et al: Antimicrobial resistance in urinary isolates from inpatients and outpatients at a tertiary care hospital in South-Kivu Province (Democratic Republic of Congo). BMC Research Notes 2014 7:374.

\section{Submit your next manuscript to BioMed Central and take full advantage of:}

- Convenient online submission

- Thorough peer review

- No space constraints or color figure charges

- Immediate publication on acceptance

- Inclusion in PubMed, CAS, Scopus and Google Scholar

- Research which is freely available for redistribution 